\title{
Assessment for Predicting Parturition in Mares Based on Prepartum Temperature Changes Using a Digital Rectal Thermometer and Microchip Transponder Thermometry Device
}

\author{
Kenji KOROSUE ${ }^{1 *}$, Harutaka MURASE ${ }^{1}$, Fumio SATO ${ }^{1)}$, Mutsuki ISHIMARU ${ }^{1)}$, Yoshiro ENDO ${ }^{1)}$ and \\ Yasuo NAMBO ${ }^{1)}$ \\ ${ }^{1)}$ Hidaka Training and Research Center, Japan Racing Association, 535-13 Aza-Nishicha, Urakawa-cho, Urakawa-gun, Hokkaido \\ 057-0171, Japan
}

(Received 1 November 2011/Accepted 25 January 2012/Published online in J-STAGE 8 February 2012)

\begin{abstract}
The purpose of this study was to observe the changes in body temperature before parturition using a wireless temperature monitoring device (WTMD) and to evaluate the usefulness of body temperature measurements using a digital rectal thermometer (DRT) and a microchip transponder thermometry device (MTTD) for predicting parturition in mares. The body temperatures using a WTMD at $0 \mathrm{hr}$ and $-1 \mathrm{hr}$ were significantly different from those at the same time on Days $1-5(P<0.01)$. The temperature differences between the morning of Day 0 and at $-3 \mathrm{hr},-2 \mathrm{hr},-1 \mathrm{hr}$ and $0 \mathrm{hr}$ using the DRT and MTTD showed a significant drop compared with the temperature differences between the morning and evening of Days $1-5(P<0.05)$. Furthermore, when the cutoff value of the temperature differences between the morning and other times was set to $\leq 0$, the sensitivities of the DRT and MTTD in the evening of Day 0 and at $-3 \mathrm{hr}$ were $43 \%$ and $100 \%$ and $71 \%$ and $86 \%$, respectively. The results suggested that monitoring the body temperature differences between morning and within $3 \mathrm{hr}$ before the time of parturition is a valuable method for predicting parturition in mares. Conversely, this method would be more useful in predicting parturition when used in combination with other observations such as the mammary gland size and waxing of the teat ends because it has nearly a $20 \%$ probability of false-positive results prior to the day of parturition.

KEY WORDS: body temperature, equine, microchip transponder thermometry device, predicting parturition.
\end{abstract}

doi: 10.1292/jvms.11-0497; J. Vet. Med. Sci. 74(7): 845-850, 2012

The average duration of gestation in mares is estimated to be from 335 to 342 days [2]. Mares typically foal within 2 weeks of this average duration; thus, the normal duration of gestation is from 320 to 365 days [18]. Measurement of the calcium concentration has become widely used in the horse industry as a method to predict parturition [3, 22]. This method has proven useful in the management of foaling mares; it does not predict whether a given mare will foal, but rather it predicts when she is not ready to foal [19, 22]. The other methods commonly used to predict parturition in mares are also unreliable and imprecise because there is considerable variation in impending parturition signals among mares. In general, signs indicating the onset of the first stage of labor, which lasts about an hour, are restlessness, sweating and reactions to the pain of uterine contractions [10]. However, there are no quantitative measurements of prepartum signs in mares.

There is evidence that several mammals show a body temperature below normal levels before parturition. A rapid fall in rectal temperature prior to parturition has been documented in cows $[17,26]$ and ewes [8]. Some studies on

*Correspondence to: Korosue, K., Hidaka Training and Research Center, Japan Racing Association, 535-13 Aza-Nishicha, Urakawa-cho, Urakawa-gun, Hokkaido 057-0171, Japan. e-mail: Kenji_Korosue@jra.go.jp

(C)2012 The Japanese Society of Veterinary Science the relationship between body temperature and parturition in mares have demonstrated that there was no change from normal that could be used to predict the time of parturition $[6,14]$. However, one of these studies showed decreases in body temperature, but these changes were of no significance because of errors associated with the use of a standard clinical thermometer. Furthermore, some studies have demonstrated that a decrease in rectal temperature was recorded in mares prior to parturition $[13,25]$.

In horses, body temperature is usually taken with a rectal thermometer. Although most horses tolerate the procedure, some are not cooperative. In these horses, placing the rectal thermometer under the tail puts the temperature taker at risk of injury from hind limb kicking. Recently, several studies demonstrated that percutaneous implantation of a thermal sensor has the capability of sensing the body temperature of horses and is more accurate compared with temperatures obtained by rectal thermometers [11, 23]. Several studies have reported the use of similar devices in goats, sheepdogs and laboratory animals $[4,11,12,15]$. These thermal sensors have the potential to offer a safer, hygienic and more rapid method of obtaining a body temperature measurement.

The purpose of this study was to observe the changes in body temperature before parturition using a wireless temperature monitoring device (WTMD) and to determine whether measurement of body temperature before parturition using a digital rectal thermometer (DRT) and a mi- 
crochip transponder thermometry device (MTTD) could be used to predict the onset of parturition.

\section{MATERIALS AND METHODS}

Animals: Seven pregnant mares, ranging in age from 4 to 13 years $(9.9 \pm 2.9$ years $)$, ranging in weight within a week before parturition from 599 to $728 \mathrm{~kg}(666 \pm 48 \mathrm{~kg})$ and ranging in gestation length from 333 to 355 days (344.4 \pm 7.7 days), were chosen for evaluating the changes in body temperature using an MTTD. Six of these pregnant mares were also chosen for evaluating the changes in body temperature using a WTMD. Another seven pregnant mares, ranging in age from 4 to 11 years $(8.2 \pm 2.6$ years $)$, ranging in weight within a week before parturition from 560 to 761 $\mathrm{kg}(655 \pm 73 \mathrm{~kg})$ and ranging in gestation length from 337 to 356 days ( $345.7 \pm 6.2$ days), were chosen for evaluating the changes in body temperature using a DRT. All mares were turned out to pasture between 08:30 and 14:30 hr, and stabled individually in box stalls overnight. The mares were monitored by a monitoring camera throughout their stay in the box stall to identify their foaling. Twelve of fourteen mares foaled between 20:00 and 24:00 hr, and another two mares foaled between 01:00 and 02:00 hr. In the two cases of foaling between 01:00 and 02:00 hr, the day of parturition (Day 0) was defined as the day before foaling. This study was approved by the Animal Care and Use Committee at Hidaka Training and Research Center.

Body temperature using a WTMD: The change in body temperature before parturition was evaluated using a wireless temperature monitoring system (Thermochron iButton DS1922L, Maxim Integrated Products, Sunnyvale, CA, U.S.A.). A WTMD was implanted beneath the skin at $5 \mathrm{~cm}$ below the upper border of the left side of the neck located halfway between the poll and withers. WTMDs were sterilized in an autoclave prior to implantation. Before starting these surgical procedures, the horses were restrained in stocks, sedated with an intravenous injection of $0.005 \mathrm{mg} /$ $\mathrm{kg}$ of medetomidine (Domitor, Nippon Zenyaku Kogyo Co., Ltd., Fukushima, Japan) and treated with lidocaine (Xylocaine injection $2 \%$, AstraZeneca K.K., Osaka, Japan) local anesthesia to reduce the stress of the surgical procedures. Aseptic techniques were applied throughout the procedures. After the surgical procedures, $1.0 \mathrm{mg} / \mathrm{kg}$ of flunixin meglumine (Banamine injection 5\%, Dainippon Sumitomo Pharma Co., Ltd., Osaka, Japan) was injected intravenously for 2 days to minimize inflammation, and a mixture of procaine penicillin $\mathrm{G}$ and dihydrostreptomycin sulfate (Mycillin Sol, $0.05 \mathrm{ml} / \mathrm{kg}$, Meiji Seika Pharma Co., Ltd., Tokyo, Japan) was injected intramuscularly for 3 days to prevent surgery-related infections. A WTMD was implanted 5 days before parturition, with the exception of one pregnant mare in which the device was implanted 2 days before parturition. The recording time between measurements was 15 min, resulting in 96 measurements taken during the night. All wireless temperature monitoring devices were removed surgically using the same procedures as described above after parturition, and the data were collected. The body temperature at the time of parturition $(0 \mathrm{hr})$ was defined as the body temperature that was recorded closest to the time when the mare foaled. The changes in body temperature before parturition using a WTMD were evaluated by comparing the temperatures on the day of parturition and the temperatures on the control days (Days 1-5), which were the mean temperatures from 5 days to 1 day before parturition. To standardize changes in body temperature, the time of parturition was set as the standard time $(0 \mathrm{hr})$ and changes in hourly body temperature were referenced to the time of parturition for $24 \mathrm{hr}$ before $(-24 \mathrm{hr})$ and to $6 \mathrm{hr}$ after the time of parturition $(+6 \mathrm{hr})$.

Body temperature using a DRT: Rectal temperature before parturition was evaluated using a data logger digital thermometer (TR-71Ui, T\&D Corporation, Nagano, Japan). Measurements were taken by inserting the probe (TR-0106, T\&D Corporation, Nagano, Japan) tip into the rectum to a depth of approximately $10 \mathrm{~cm}$, and it was kept in the rectum for at least $5 \mathrm{~min}$. Rectal temperatures were recorded twice daily, between 06:00 and 07:00 hr (morning temperatures) and again between 16:00 and 17:00 hr (evening temperatures), from 5 days before parturition until the day of parturition. Furthermore, rectal temperatures were recorded continuously from $3 \mathrm{hr}$ before the time of parturition. The recording time between measurements was $1 \mathrm{~min}$.

Body temperature using an MTTD: A thermal sensor of an MTTD (Lifechip Bio-Thermo temperature-sensing chip, Destron Fearing, Digital Angel Corporation, South St. Paul, MN, U.S.A.) was placed percutaneously according to the recommendations of the manufacturer in the left side of the nuchal ligament located halfway between the poll and withers. A microchip was injected at the same time as when a WTMD was implanted or earlier, and all microchips were placed 5 days before parturition. Before injection of the microchip, the horses were tranquilized with an intravenous injection of $0.005 \mathrm{mg} / \mathrm{kg}$ of medetomidine. Temperature measurements from the MTTD were obtained using a compatible reader (Pocket Reader EX, Destron Fearing, Digital Angel Corporation). Replicate temperatures were obtained by taking two readings in succession. The temperature taken by the MTTD was recorded twice daily, between 06:00 and 07:00 hr (morning temperatures) and again between 16:00 and 17:00 $\mathrm{hr}$ (evening temperatures), from 5 days before parturition until the day of parturition. Furthermore, the temperature taken by the MTTD was recorded at 30-min intervals from $3 \mathrm{hr}$ before the time of parturition. The temperature at the time of parturition $(0 \mathrm{hr})$ was defined as the temperature that was recorded closest to the time when the mare foaled. The usefulness of predicting the onset of parturition using both a DRT and MTTD was evaluated by comparing the temperature differences between morning and evening or between hourly temperatures $(-3 \mathrm{hr},-2 \mathrm{hr},-1 \mathrm{hr}$ and $0 \mathrm{hr}$ ) before the time of parturition and the temperature differences between morning and evening temperatures on the control days (Days $1-5)$, which were the mean temperatures from 5 days to 1 day before parturition.

Accuracy of each thermometry device; The accuracy of WTMDs, DRTs and MTTDs was tested against a mercuryin-glass thermometer using a water bath (Racomace model 


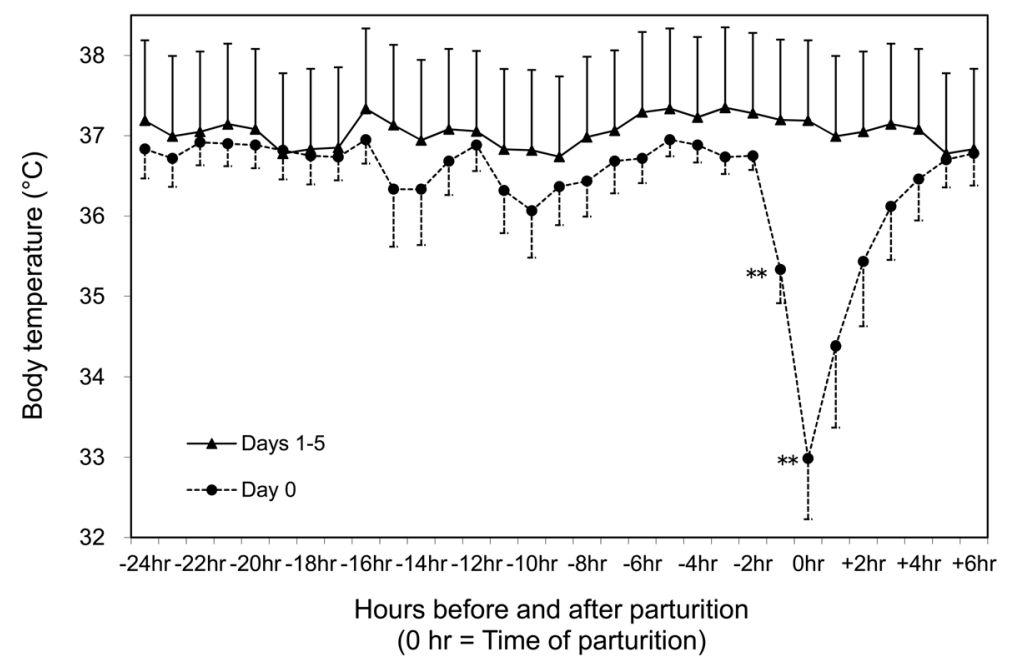

Fig. 1. Changes in body temperature based on the time of parturition $(0 \mathrm{hr})$ on the day of parturition from $24 \mathrm{hr}$ before and $6 \mathrm{hr}$ after the time of parturition and on the control days (Day 1-5) using a wireless temperature monitoring device (WTMD) implanted beneath the skin. Data represent the mean and SEM. Asterisks indicate significant differences between the body temperatures on Day 0 and those at the same time on Days 1-5 (** $P<0.01)$.

HT-90D, Iuchi Seieido Co., Ltd., Tokyo, Japan) representing 4 different temperatures, i.e., $34,36,38$ and $40^{\circ} \mathrm{C}$.

Statistical analysis: The results were expressed as means \pm SD. The cutoff value of sensitivity and specificity for the temperature differences between morning and evening or other times ( $-3 \mathrm{hr},-2 \mathrm{hr}$ and $-1 \mathrm{hr}$ on Day 0$)$ was assessed by use of receiver operating characteristic (ROC) curve analysis with the ROCKIT $0.9 \beta$ Beta Version software (Kurt Rossmann Laboratories for Radiologic Image Research) [21]. On the basis of measures of minimal distance to the upper left corner of the ROC curve of the temperature differences between the morning and evening on Day 0 and between the morning and $-3 \mathrm{hr}$ on Day $0, \leq 0$ was more suitable as the cutoff value for measurement by using a DRT or MTTD compared with $\leq 0.1$ and $\leq-0.1$.

Statistical analyses were performed using the JMP v. 5.0.1a software (SAS Institute Inc., Cary, NC, U.S.A.). A paired $t$ test was applied to compare the changes in temperature on the day of parturition and on the control days using a WTMD. A one-way repeated-measures analysis of variance test was applied to compare the temperature differences on the day of parturition and on the control days using both a DRT and MTTD. When significant differences were identified, the Wilcoxon signed-rank test was applied. Probability values of less than 0.05 were considered statistically significant.

\section{RESULTS}

Changes in body temperature before parturition using a WTMD: The accuracy of measurements for 2 WTMDs, which were used in this study, was found to be within the range of $\pm 0.1^{\circ} \mathrm{C}$. Repeatability was also found to be within the range of $\pm 0.1^{\circ} \mathrm{C}$. The changes in body temperature using a WTMD based on the time of parturition $(0 \mathrm{hr})$ on the day of parturition from $24 \mathrm{hr}$ before and $6 \mathrm{hr}$ after the time of parturition, compared with the changes in them on the control days (Day 1-5), are shown in Fig. 1. The body temperatures between $-15 \mathrm{hr}$ to $-2 \mathrm{hr}$ had a tendency to be lower than those at the same time on Days 1-5; however, these changes were not statistically significant. Conversely, the body temperatures at $0 \mathrm{hr}$ and $-1 \mathrm{hr}$ were significantly different from those at the same time on Days 1-5 $(P<0.01)$.

Changes in body temperature before parturition using a DRT: The accuracy of measurements for 2 DRTs, which were used in this study, was found to be within the range of $-0.1^{\circ} \mathrm{C}$. Repeatability was also found to be within the range of $-0.1^{\circ} \mathrm{C}$. The changes in body temperature and the mean temperature differences at each time on Days 1-5 and Day 0 using a DRT are shown in Table 1. The body temperatures at $-3 \mathrm{hr},-2 \mathrm{hr},-1 \mathrm{hr}$ and $0 \mathrm{hr}$ showed a significant drop when compared with those of the mornings and evenings of Days 1-5 $(P<0.05)$. The differences between the morning of Day 0 and at $-3 \mathrm{hr},-2 \mathrm{hr},-1 \mathrm{hr}$ and $0 \mathrm{hr}$ showed a significant drop when compared with the differences between the mornings and evenings of Days $1-5$ and Day $0(P<0.05)$. The sensitivities of the body temperatures obtained on the evening of Day 0 , at $-3 \mathrm{hr}$ and at $-2 \mathrm{hr}$ were $43 \%, 100 \%$, and $100 \%$, respectively (Table 2). Conversely, the specificity of the body temperatures obtained from Days 1-5 was $80 \%$ (Table 2).

Changes in body temperature before parturition using an MTTD: The accuracy of measurements for 2 MTTDs, which were the same products used in this study, was found to be 
Table 1. Changes in body temperature at each time on Day 0 and Days 1-5 and changes in the mean temperature differences between the morning and other times (evening, $-3 \mathrm{hr},-2 \mathrm{hr},-1 \mathrm{hr}$ and $0 \mathrm{hr}$ ) using a digital rectal thermometer (DRT) and a microchip transponder thermometry device (MTTD)

\begin{tabular}{|c|c|c|c|c|}
\hline \multirow{2}{*}{$\begin{array}{l}\text { Days and hours relative } \\
\text { to parturition }\end{array}$} & \multicolumn{2}{|c|}{$\begin{array}{l}\text { Digital rectal thermometer } \\
\text { (DRT) }\end{array}$} & \multicolumn{2}{|c|}{$\begin{array}{l}\text { Microchip transponder thermometry } \\
\text { device (MTTD) }\end{array}$} \\
\hline & $\begin{array}{l}\text { Temperature } \\
\left({ }^{\circ} \mathrm{C}\right)\end{array}$ & $\begin{array}{c}\text { Temperature } \\
\text { difference }\left({ }^{\circ} \mathrm{C}\right)\end{array}$ & $\begin{array}{l}\text { Temperature } \\
\left({ }^{\circ} \mathrm{C}\right)\end{array}$ & $\begin{array}{l}\text { Temperature } \\
\text { difference }\left({ }^{\circ} \mathrm{C}\right)\end{array}$ \\
\hline Days $1-5$ & & $0.15 \pm 0.04^{\text {a) }}$ & & $0.39 \pm 0.15^{\text {a) }}$ \\
\hline Morning & $37.66 \pm 0.02^{\text {a) }}$ & & $\left.37.03 \pm 0.08^{\mathrm{a}, \mathrm{b}}\right)$ & \\
\hline Evening & $37.86 \pm 0.02$ a) & & $37.42 \pm 0.06^{\text {a) }}$ & \\
\hline Day 0 & & $0.14 \pm 0.07$ a) & & $\left.-0.06 \pm 0.15^{\mathrm{a}, \mathrm{b}}\right)$ \\
\hline Morning & $37.46 \pm 0.08^{\mathrm{a}, \mathrm{b})}$ & & $\left.37.10 \pm 0.22^{\mathrm{a}, \mathrm{b}}\right)$ & \\
\hline Evening & $37.60 \pm 0.08^{\mathrm{a}, \mathrm{c})}$ & & $\left.37.04 \pm 0.20^{\mathrm{a}, \mathrm{b}}\right)$ & \\
\hline$-3 \mathrm{hr}$ & $37.29 \pm 0.10^{\mathrm{b}, \mathrm{c}, \mathrm{d})}$ & $-0.17 \pm 0.09^{b)}$ & $36.91 \pm 0.21^{\mathrm{a}, \mathrm{c}}$ & $-0.19 \pm 0.12^{b, c)}$ \\
\hline$-2 \mathrm{hr}$ & $37.24 \pm 0.09^{b, d)}$ & $-0.21 \pm 0.09^{b, c)}$ & $36.77 \pm 0.18^{\mathrm{a}, \mathrm{c}}$ & $-0.28 \pm 0.11^{b, c)}$ \\
\hline$-1 \mathrm{hr}$ & $37.09 \pm 0.08^{\mathrm{d})}$ & $-0.37 \pm 0.05^{\mathrm{c})}$ & $36.53 \pm 0.18^{b, c)}$ & $-0.54 \pm 0.12^{\mathrm{c}, \mathrm{d})}$ \\
\hline $0 \mathrm{hr}$ & $36.70 \pm 0.13$ d) & $-0.76 \pm 0.10^{\text {d) }}$ & $35.81 \pm 0.49^{c)}$ & $-1.29 \pm 0.37^{\mathrm{d}, \mathrm{e})}$ \\
\hline
\end{tabular}

Values are expressed as the mean \pm SD. Morning: Morning temperatures recorded between 06:00 and 07:00 hr. Evening: Evening temperature recorded between 16:00 and 17:00 hr. $0 \mathrm{hr}$ : Time of parturition. a-e) Values within a column with different superscripts are significantly different $(P<0.05)$.

Table 2. Specificity of Days 1-5 and sensitivities of the evening of Day 0 and at other times ( $-3 \mathrm{hr},-2 \mathrm{hr}$ and $-1 \mathrm{hr}$ on Day 0$)$ of both the digital rectal thermometer (DRT) and microchip transponder thermometry device (MTTD) in the case that the cutoff value of the temperature differences between morning and evening or other times was set to $\leq 0$

\begin{tabular}{|c|c|c|c|c|c|c|c|c|c|c|}
\hline & \multicolumn{5}{|c|}{$\begin{array}{l}\text { Digital rectal thermometer } \\
\text { (DRT) }\end{array}$} & \multicolumn{5}{|c|}{$\begin{array}{c}\text { Microchip transponder } \\
\text { thermometry device (MTTD) }\end{array}$} \\
\hline & \multirow{2}{*}{ Days $1-5$} & \multicolumn{4}{|c|}{ Day 0} & \multirow{2}{*}{ Days $1-5$} & \multicolumn{4}{|c|}{ Day 0} \\
\hline & & Evening & $-3 \mathrm{hr}$ & $-2 \mathrm{hr}$ & $-1 \mathrm{hr}$ & & Evening & $-3 \mathrm{hr}$ & $-2 \mathrm{hr}$ & $-1 \mathrm{hr}$ \\
\hline Number of TPs & - & 3 & 7 & 7 & 7 & - & 5 & 6 & 7 & 7 \\
\hline Number of FPs & 7 & - & - & - & - & 8 & - & - & - & - \\
\hline Number of FNs & - & 4 & 0 & 0 & 0 & - & 2 & 1 & 0 & 0 \\
\hline Number of TNs & 28 & - & - & - & - & 27 & - & - & - & - \\
\hline Sensitivity & - & $43 \%$ & $100 \%$ & $100 \%$ & $100 \%$ & - & $71 \%$ & $86 \%$ & $100 \%$ & $100 \%$ \\
\hline Specificity & $80 \%$ & - & - & - & - & $77 \%$ & - & - & - & - \\
\hline
\end{tabular}

Evening: Evening temperature recorded between 16:00 and 17:00 hr. TP: True-positive test value. FP: False-positive test value. FN: False-negative test value. TN: True-negative test value.

within the range from +0.1 to $+0.3^{\circ} \mathrm{C}$. In contrast, repeatability was found to be within the range of $\pm 0.1^{\circ} \mathrm{C}$. The changes in body temperature and the mean temperature differences at each time on Days 1-5 and Day 0 using an MTTD are shown in Table 1. The differences between the morning of Day 0 and at $-3 \mathrm{hr},-2 \mathrm{hr},-1 \mathrm{hr}$ and $0 \mathrm{hr}$ showed a significant drop when compared with the differences between the mornings and evenings of Days $1-5(P<0.05)$. The sensitivities of the body temperatures obtained on the evening of Day 0 , at $-3 \mathrm{hr}$ and at $-2 \mathrm{hr}$ were $71 \%, 86 \%$ and $100 \%$, respectively (Table 2). Conversely, the specificity of the body temperatures obtained from Days 1-5 was 77\% (Table 2).

\section{DISCUSSION}

This study is the first to demonstrate the hourly changes in body temperature for $24 \mathrm{hr}$ before the time of parturition and to demonstrate the usefulness of predicting the onset of par- turition using an MTTD. The results of this study suggested that monitoring the body temperature differences between morning and within $3 \mathrm{hr}$ before the time of parturition can be considered a valuable method for predicting parturition in mares.

In this study, the body temperatures between $15 \mathrm{hr}$ to $2 \mathrm{hr}$ before the time of parturition using a WTMD had a tendency to be lower than those at the same time on Days 1-5, and the body temperatures at $1 \mathrm{hr}$ before parturition and at the time of parturition were significantly different from those at the same time on Days $1-5(P<0.01)$. Furthermore, the body temperatures at $-3 \mathrm{hr},-2 \mathrm{hr},-1 \mathrm{hr}$ and $0 \mathrm{hr}$ using a DRT showed a significant drop when compared with those of Days 1-5. These results demonstrated findings similar to those in previous reports, in which a decrease in rectal temperature was recorded prior to parturition $[13,25]$. Conversely, with the MTTD, only the body temperatures at 0 $\mathrm{hr}$ showed a significant drop; those at $3 \mathrm{hr}$ before the time 
of parturition showed no significant drop when compared with those of Days 1-5. Thus, it was difficult to predict the onset of parturition based on the changes in body temperature itself. Therefore, the temperature differences between morning and evening or hourly temperatures $(-3 \mathrm{hr},-2 \mathrm{hr}$, $-1 \mathrm{hr}$ and $0 \mathrm{hr}$ ) before the time of parturition were compared to make predicting the onset of parturition easier. The temperature differences between the morning of Day 0 and at $-3 \mathrm{hr},-2 \mathrm{hr},-1 \mathrm{hr}$ and $0 \mathrm{hr}$ using both a DRT and MTTD were significantly different from the differences between the mornings and evenings of Days 1-5. Furthermore, when the cutoff value of the temperature differences was set to $\leq 0$, the sensitivities using a DRT on the evening of Day 0 and at -3 hr were $43 \%$ and $100 \%$, respectively, and the sensitivities in using an MTTD on the evening of Day 0 and at $-3 \mathrm{hr}$ were $71 \%$ and $86 \%$, respectively. These results demonstrate that the temperature differences between the morning and evening of Day 0 or $-3 \mathrm{hr}$ are useful in predicting the onset of parturition. In other words, this suggests that if the temperature of evening onward was the same as or lower than that of the morning, the mares may be preparing to foal that night or at midnight. However, the DRT and MTTD methods had false-positive rates of $20 \%$ and $23 \%$, respectively, during Days 1 to 5.

An MTTD is easy to implant, exhibits little migration and provides rapid readings of body temperature. Results of previous studies on thermal sensors in horses indicate that they provide a more variable readings than rectal thermometers and temperature readings below those of rectal thermometers $[11,23]$. Furthermore, one of these studies indicated that the sensitivity of a thermal sensor for detection of fever defined as $\geq 38.9^{\circ} \mathrm{C}$ significantly differed in warmer ambient temperatures $\left(>15.6^{\circ} \mathrm{C}\right)$ compared with colder ambient temperatures $\left(\leq 15.6^{\circ} \mathrm{C}\right)$. In the present study, the thermal sensor also usually underestimated rectal temperature. This result was considered to be due to the ambient temperature outside ranging from $-8.9^{\circ} \mathrm{C}$ to $11.8^{\circ} \mathrm{C}$. Thus, an MTTD implanted in the nuchal ligament may not be useful in detecting fevers in cooler ambient temperatures. However, it is considered to be an available method in the case of monitoring the changes in body temperatures, such as in this study, for predicting parturition in mares.

There is evidence that several mammals show body temperatures below normal levels before parturition $[7,8,17$, 26]. Some studies have indicated that fetal lambs lose $80 \%$ to $85 \%$ of their heat via transfer to placenta and that the other $15 \%$ to $20 \%$ is lost via transfer through the uterine wall [9, 24]. Blood flow to the placenta is directly affected by maternal temperature, and this effect influences heat dissipation by the fetus [24]. In addition, fetal lamb temperature increases before lambing and decreases approximately $1.5^{\circ} \mathrm{C}$ within $20 \mathrm{~min}$ after lambing, even in a temperature-controlled environment [16], indicating that this mechanism may protect newborn lambs from hyperthermia. Furthermore, one study reported that fetal temperature continues to increase through parturition because myometrial contractions also decrease uterine blood flow and heat dissipation by the fetus [1]. The results of the present study suggested that similar mecha- nisms may also occur in horses. Conversely, progesterone is known to affect thermoregulation. A high correlation between decreasing levels of progesterone and temperature drop was found in beagle bitches [5]. A similar drop in total progestins has been documented in mares [20], but the correlation of progesterone with temperature has not been studied. Further research is needed to clarify this relationship.

In conclusion, the results of this study demonstrate that monitoring the body temperature differences between morning and evening onward can be a valuable method for predicting parturition in mares. In other words, if the temperature in the evening onward is the same as or lower than that of the morning, the mares may be preparing to foal that night or at midnight. In particular, an MTTD is useful in measuring body temperature in pregnant mares because it is easy to implant and provides rapid readings of body temperature. Conversely, monitoring body temperature differences alone are not enough to predict the day of parturition reliably and precisely because this method has nearly a $20 \%$ probability of false-positive results prior to the day of parturition. Therefore, this method would be more useful in predicting parturition when used in combination with other observations of parturition prediction such as mammary gland size and waxing of the teat ends.

\section{REFERENCES}

1. Brar, H. S., Platt, L. D., DeVore, G. R., Horenstein, J. and Medearis, A. L. 1988. Qualitative assessment of maternal uterine and fetal umbilical artery blood flow and resistance in laboring patients by Doppler velocimetry. Am. J. Obstet. Gynecol. 158: 952-956. [Medline]

2. Card, C. E. 1993. Parturition. pp. 567-573. In: Equine Reproduction (McKinnon, A.O. and Voss, J.L. eds.), Lea \& Febiger, Philadelphia.

3. Cash, R. S., Ousey, J. C. and Rossdale, P. D. 1985. Rapid strip test method to assist management of foaling mares. Equine Vet. J. 17: 61-62. [Medline] [CrossRef]

4. Chen, P. H. and White, C. E. 2006. Comparison of rectal, microchip transponder, and infrared thermometry techniques for obtaining body temperature in the laboratory rabbit (Oryctolagus cuniculus). J. Am. Assoc. Lab. Anim. Sci. 45: 57-63. [Medline]

5. Concannon, P. W., Powers, M. E., Holder, W. and Hansel, W. 1977. Pregnancy and parturition in the bitch. Biol. Reprod. 16: 517-526. [Medline]

6. Cox, J. E. 1969. Rectal temperature as indicator of approaching parturition in the mare. Equine Vet. J. 1: 174-176. [CrossRef]

7. Eliason, H. L. and Fewell, J. E. 1997. Thermoregulatory control during pregnancy and lactation in rats. J. Appl. Physiol. 83: 837-844. [Medline]

8. Ewbank, R. 1969. The fall in rectal temperature seen before parturition in sheep. J. Reprod. Fertil. 19: 569-571. [Medline] [CrossRef]

9. Gilbert, R. D., Schroder, H., Kawamura, T., Dale, P. S. and Power, G. G. 1985. Heat transfer pathways between fetal lamb and ewe. J. Appl. Physiol. 59: 634-638. [Medline]

10. Ginther, O. J. 1992. Parturition, Puerperium, and Puberty. pp. 459-460. In: Reproductive Biology of the Mare, 2nd ed., Equiservices, Wisconsin.

11. Goodwin, S. 1998. Comparison of body temperatures of goats, horses, and sheep measured with a tympanic infrared thermom- 
eter, an implantable microchip transponder, and a rectal thermometer. Contemp. Top. Lab. Anim. Sci. 37: 51-55. [Medline]

12. Greer, R. J., Cohn, L. A., Dodam, J. R., Wagner-Mann, C. C. and Mann, F. A. 2007. Comparison of three methods of temperature measurement in hypothermic, euthermic, and hyperthermic dogs. J. Am. Vet. Med. Assoc. 230: 1841-1848. [Medline] [CrossRef]

13. Haluska, G. J. and Wilkins, K. 1989. Predictive utility of prepartum temperature changes in the mare. Equine Vet. J. 21: 116118. [Medline] [CrossRef]

14. Jeffcott, L. B. 1972. Observations on parturition in crossbred mares. Equine Vet. J. 4: 209-213. [CrossRef]

15. Kort, W. J., Hekking-Weijma, J. M., TenKate, M. T., Sorm, V. and VanStrik, R. 1998. A microchip implant system as a method to determine body temperature of terminally ill rats and mice. Lab. Anim. 32: 260-269. [Medline] [CrossRef]

16. Laburn, H. P., Goelst, K. and Mitchell, D. 1994. Body temperatures of lambs and their mothers measured by radio-telemetry during parturition. Experientia 50: 708-711. [Medline] [CrossRef]

17. Lammoglia, M. A., Bellows, R. A., Short, R. E., Bellows, S. E., Bighorn, E. G., Stevenson, J. S. and Randel, R. D. 1997. Body temperature and endocrine interactions before and after calving in beef cows. J. Anim. Sci. 75: 2526-2534. [Medline]

18. LeBlanc, M. M. 1993. Induction of parturition. pp. 574-577. In: Equine Reproduction (McKinnon, A.O. and Voss, J.L. eds.), Lea \& Febiger, Philadelphia.

19. Ley, W. B., Bowen, J. M., Purswell, B. J., Irby, M. and Greive-
Crandell, K. 1993. The sensitivity, specificity and predictive value of measuring calcium carbonate in mares' prepartum mammary secretions. Theriogenology 40: 189-198. [Medline] [CrossRef]

20. Lovell, J. D., Stabenfeldt, G. H., Hughes, J. P. and Evans, J. W. 1975. Endocrine patterns of the mare at term. J. Reprod. Fertil. Suppl. 23: 449-456. [Medline]

21. Metz, C. E. 1986. ROC methodology in radiologic imaging. Invest. Radiol. 21: 720-733. [Medline] [CrossRef]

22. Ousey, J. C., Delclaux, M. and Rossdale, P. D. 1989. Evaluation of three strip tests for measuring electrolytes in mares' pre-partum mammary secretions and for predicting parturition. Equine Vet. J. 21: 196-200. [Medline] [CrossRef]

23. Robinson, T. R., Hussey, S. B., Hill, A. E., Heckendorf, C. C., Stricklin, J. B. and Traub-Dargatz, J. L. 2008. Comparison of temperature readings from a percutaneous thermal sensing microchip with temperature readings from a digital rectal thermometer in equids. J. Am. Vet. Med. Assoc. 233: 613-617. [Medline] [CrossRef]

24. Schroder, H., Gilbert, R. D. and Power, G. G. 1988. Computer model of fetal-maternal heat exchange in sheep. J. Appl. Physiol. 65: 460-468. [Medline]

25. Shaw, E. B., Houpt, K. A. and Holmes, D. F. 1988. Body temperature and behaviour of mares during the last two weeks of pregnancy. Equine Vet. J. 20: 199-202. [Medline] [CrossRef]

26. Wrenn, T. R., Bitman, J. and Sykes, J. F. 1958. Body temperature variation in daily cattle during the estrous cycle and pregnancy. J. Dairy Sci. 41: 1071-1076. [CrossRef] 